\title{
Imposto sobre Circulação de Mercadorias e Serviços Socioambiental: incentivos institucionais e legislação ambiental no Brasil
}

\author{
Alexandrina Sobreira de Moura \\ Fundação Joaquim Nabuco e Universidade Federal de Pernambuco
}

\begin{abstract}
O crescimento sustentável dos municípios brasileiros deixou de ser um aspecto desejável para se constituir em um requisito para o país, visto o surto de desenvolvimento que o Brasil vem atravessando nos últimos anos. Não obstante, a responsabilidade sobre a fiscalização e regulação ambiental do crescimento e da produção tem se concentrado cada vez mais nos atores locais. Nesse contexto, o Imposto sobre Circulação de Mercadorias e Serviços (ICMS) Socioambiental se destaca como um dos principais mecanismos de regulação e ordenamento dos processos produtivos em nível local. Este trabalho analisa os aspectos jurídico-institucionais dessa iniciativa, assim como traça um quadro comparativo entre as distintas legislações estaduais. Também é feita uma análise de seu trajeto histórico e de sua evolução jurídica. Buscou-se, particularmente, traçar um panorama nacional de como as diferentes concepções de sustentabilidade foram operacionalizadas pelas legislações estaduais, gerando diferentes estruturas de incentivos institucionais.
\end{abstract}

Palavras-chave: instrumentos econômicos; meio ambiente; Lei ICMS.

IVA ambiental: incentivos institucionales y legislación ambiental en Brasil

El rápido crecimiento económico experimentado por Brasil durante los últimos años ha transformado la sustentabilidad de sus municipios de ser sólo un aspecto deseable a ser un requisito para el desarrollo del país. No obstante, la responsabilidad de supervisión y de regulación ambiental del crecimiento y de la producción se ha transferido progresivamente hacia los actores gubernamentales locales. En este escenario, el Imposto sobre Circulação de Mercadorias e Serviços (ICMS) Ambiental se erige como uno de los principales mecanismos de regulación de la producción y de gestión ambiental a nivel local. Este artículo examina los aspectos legales e institucionales de esta iniciativa, y de igual forma describe comparativamente las diferencias entre las legislaciones estatales que siguen este modelo. Asimismo se analiza la trayectoria histórica de su evolución legal, así como los resultados que las últimas inves-

DOI: http://dx.doi.org/10.1590/0034-76121677

Artigo recebido em 6 ago. 2013 e aceito em 15 set. 2014.

(cc) BY-NC

Agradeço a Beatriz Pedrosa (Fundação Joaquim Nabuco), a Luis Honorato da Silva Júnior (UnB) e a Felipe Oriá (mestrando da Harvard Kennedy School) pelas críticas, que contribuíram para a elaboração deste artigo. 
tigaciones sobre el tema han alcanzado, esto a fin de desprender conclusiones sobre la eficacia de esta política y de esbozar las perspectivas para la evolución de este instrumento.

Palabras clave: los instrumentos económicos; medio Ambiente; Ley ICMS.

Tax over movement of goods and socio-environmental service: institutional incentives and environmental legislation in Brazil

The sustainable growth of Brazilian municipalities has turned the sustainability of its municipalities from a desirable aspect into a requirement for the country's development, taking into consideration the Brazilian growth boom in the recent years. Nevertheless, the responsibility for the supervision and environmental regulation of growth and production has been increasingly transferred to local actors. In this scenario, the tax over movement of goods and services (Imposto sobre Circulação de Mercadoria e Serviço - ICMS) stands as one of the main mechanisms of regulation and planning of the productive processes at the local level. This paper examines the legal and institutional aspects of this initiative, as well as comparatively outlines the differences between state legislations. It also analyses the historical path of their legal development. Furthermore, particularly the research tried to outline a national panoramic view of how different conceptions of sustainability were put into operation by the state legislations, creating different structures of institutional incentives.

KEYWORDs: economic instruments; environment; ICMS Law.

\section{Introdução}

O Imposto sobre Circulação de Mercadorias e Serviços (ICMS) Socioambiental, ainda conhecido como ICMS Ecológico ou Verde, é hoje um dos principais instrumentos de gestão ambiental vigentes no Brasil. Adota-se, neste artigo, a nomenclatura Socioambiental em razão de sua abrangência às questões sociais como variáveis na distribuição do imposto (Pernambuco, 2006). Esse mecanismo se destaca não apenas por ser um dos únicos tributos com a distribuição pautada por critérios ambientais, mas pelo êxito que tem alcançado ao comprometer atores locais com políticas de preservação ambiental. O fato de chegar ao extremo da cadeia administrativa, gerando incentivo direto para os gestores municipais, é um fator essencial para o sucesso dessa iniciativa.

Esse sucesso só tem sido possível devido ao protagonismo dos governos estaduais em promover uma legislação tributária ambientalmente responsável, que vem se difundindo há algum tempo no plano nacional e ganhando momentum com o passar dos anos, e a quantificação de seus benefícios (Silva Júnior et al., 2013, 2010; Silva Júnior e Sobral, 2014). A reprodução dessa iniciativa por diversos estados brasileiros, cada qual incorporando distintas concepções de sustentabilidade e responsabilidade ambiental, gerou um corpo normativo repleto de particularidades, sendo o objeto do presente trabalho.

Pretende-se analisar a evolução jurídico-institucional do ICMS Socioambiental sob uma perspectiva cronológica, bem como por meio de comparações transversais entre as diversas abordagens que os estados brasileiros têm dado à questão. Também serão discutidos alguns 
dos critérios-chave dessa política e apresentadas algumas perspectivas para os próximos anos. Buscou-se focalizar o caráter jurídico-institucional dessa ação, incorporando os debates teóricos acerca do tema, em especial a discussão neoinstitucional sobre a interação entre incentivos econômicos e as estruturas políticas estabelecidas. Da mesma forma, será vista a análise normativa pelos resultados alcançados por meio de pesquisas empíricas realizadas desde o início dessa iniciativa, na década de 1990, que já permitem conclusões mais precisas sobre os rumos desse instrumento econômico de gestão ambiental.

A importância da questão ambiental tem aumentado de maneira exponencial entre atores públicos. Particularmente na última década, diversas esferas do governo passaram a considerar o problema como uma questão de Estado e vêm atribuindo a ela sua devida importância. Não obstante, pode-se constatar claramente uma disparidade entre o nível de comprometimento das instâncias inferiores de governo, quando comparadas às esferas mais altas. Por lidarem com incentivos localizados e de curto prazo, os governos locais, nesse caso os municípios, têm sistematicamente encontrado dificuldades em incorporar macroproblemas estruturais, tal como a questão ambiental, em suas agendas, independentemente do nível de comprometimento de seus atores políticos.

Nesse sentido, o ICMS Socioambiental criou o elo que permitiu transferir preocupações normalmente restritas à seara do governo federal para uma gestão direta por parte dos municípios. Isso se deu por intermédio dos governos estaduais, os quais serviram como intermediadores diretos desses incentivos, adequando-os às realidades ambientais de seus estados. O corpo normativo produzido pela iniciativa do ICMS Socioambiental, reproduzido em diversos estados brasileiros, reflete essas disparidades, principalmente nos critérios que usa para a distribuição do tributo. Essas diferenças chegam a refletir-se em diferenças no próprio conceito de sustentabilidade operacionalizado nesses diplomas legais. Tais variações serão discutidas em mais detalhe ao longo deste trabalho.

Por último, salienta-se a importância de um estudo aprofundado desse instrumento nas esferas social, econômica, política e jurídica. A justificativa para tanto é o próprio nível de difusão do mesmo. Em todas as regiões brasileiras, à exceção do Nordeste, o ICMS Socioambiental se encontra presente em mais da metade dos estados. A região Centro-Oeste é a única em que essa nova forma de distribuição do tributo foi implantada em todos os estados. Nas regiões Sul e Sudeste, apenas Santa Catarina e Espírito Santo ainda não incorporaram esse mecanismo às suas legislações estaduais.

O caso do Nordeste é bastante particular, onde apenas três dos nove estados da região adotaram esse mecanismo. Entre esses três, apenas o Piauí reservou a alíquota do tributo para questões estritamente ambientais, enquanto os outros dois estados, Pernambuco e Ceará, enfatizaram mais o caráter social do mesmo. A riqueza desse mecanismo é o fato de permitir relevância aos estados à liberdade de definir quais as ações prioritárias a serem desenvolvidas pelos municípios. Entretanto, é importante ressaltar que, além da justificativa do atendimento às necessidades sociais, é importante que o ICMS Socioambiental seja utilizado como um critério para um conceito de sustentabilidade de longo prazo e não como um mecanismo de 
promoção e financiamento da agenda política dos governos estaduais. Tais considerações serão retomadas ao longo da exposição.

\section{Um breve histórico}

O destaque que assume o pioneirismo do Paraná no contexto brasileiro se deve ao fato de o país contar com uma incipiente rede de tributos e incentivos econômicos orientados segundo critérios ambientais. Os poucos mecanismos existentes voltados para uma lógica de preservação ambiental estiveram majoritariamente orientados segundo motivações arrecadatórias. Além disso, muitas dessas iniciativas consistiam em políticas locais e pontuais, que não possuíam sistematização ou capacidade de replicação em nível nacional (Loureiro, 1997).

Desde a Constituição Federal de 1988, alguns incentivos econômicos começaram a assumir uma maior importância, como mecanismos de controle ambiental, com destaque para as taxas vinculadas ao uso de recursos renováveis, as taxas florestais, as taxas sobre resíduos sólidos, os esquemas de depósito-reembolso, os subsídios creditícios e a isenção fiscal. Entretanto, como já foram mencionados, tais mecanismos são orientados por critérios arrecadatórios e os recursos advindos dos mesmos não são necessariamente destinados a ações de preservação ambiental.

Entre esses elementos destaca-se a participação garantida pelo art. 20 da Constituição Federal aos estados e municípios no resultado da exploração de petróleo, gás natural e recursos hídricos para fins de geração de energia elétrica (Brasil, 1988). Ainda assim, tais repasses não estão condicionados a investimentos equivalentes por parte dessas instâncias de governo em ações de preservação ambiental, corroborando a afirmativa de que "o que vem obtendo mais êxito no âmbito das políticas ambientais federais é a utilização de isenções e ajudas financeiras, notadamente através da concessão de vantagens fiscais vinculadas ao Imposto Territorial Rural" (Tupiassu, 2006:181). É nesse cenário de baixo ativismo estatal na busca de, se não soluções, ao menos incentivos para um maior comprometimento das instâncias locais com as questões ambientais que surge, em 1991, a iniciativa paranaense do ICMS Socioambiental e o que explica, em grande medida, seu sucesso.

\section{O ICMS Socioambiental}

O ICMS Socioambiental é um instrumento econômico de gestão ambiental que busca compensar e premiar os municípios que se destacam por boas práticas ambientais (Jatobá, 2003). É um instrumento de compensação fiscal que recentemente vem sendo tratado como um instrumento de pagamento por serviços ambientais (PSA). Sua adoção foi recomendada pela Agenda 21 brasileira (Jatobá e Sobreira de Moura, 2009).

\footnotetext{
${ }^{1}$ Ver, a respeito, a Lei no ${ }^{8} 8.847 / 1993$.
} 
O ICMS é o mais importante imposto de titularidade dos estados. O ICMS Socioambiental consiste na regulação dos critérios do repasse de parte dos 25\% do ICMS arrecadado pelos estados e transferido aos municípios. Esse repasse baseia-se em critérios econômicos, demográficos, sociais e ambientais. Cada estado tem legislação própria acerca da parcela a que tem direito legal de distribuir, correspondendo a 25\% do montante do ICMS transferido aos municípios, devendo os outros 75\% ser repartidos segundo critério econômico, ou seja, do valor agregado fiscal. É justamente nos $25 \%$ restantes que podem ser concebidos critérios socioambientais para a distribuição desse imposto sem, no entanto, gerar novas despesas para os estados. Estudos do Instituto Brasileiro de Geografia e Estatística (IBGE) identificam o ICMS ambiental como a principal fonte de recursos ambientais para os municípios (Jatobá e Sobreira de Moura, 2009:71).

As alíquotas descritas se baseiam no art. 158, da Constituição Federal de 1988, reproduzido a seguir:

Art. 158. Pertencem aos Municípios:

IV — vinte e cinco por cento do produto da arrecadação do imposto do Estado sobre operações relativas à circulação de mercadorias e sobre prestações de serviços de transporte interestadual e intermunicipal e de comunicação.

Parágrafo único. As parcelas de receita pertencentes aos Municípios, mencionadas no inciso IV, serão creditadas conforme os seguintes critérios:

I — três quartos, no mínimo, na proporção do valor adicionado nas operações relativas à circulação de mercadorias e nas prestações de serviços, realizadas em seus territórios;

II - até um quarto, de acordo com o que dispuser lei estadual ou, no caso dos Territórios, lei federal. (Brasil, 1988)

Ainda que o tamanho da população e critérios econômicos específicos às realidades estaduais continuem sendo os responsáveis pela maior porcentagem de distribuição do ICMS, critérios ambientais vêm progressivamente ganhando espaço na distribuição desse tributo. Não obstante, a própria compreensão dos estados quanto às ações prioritárias em matéria de preservação ambiental ainda é alvo de debates. Os instrumentos normativos nomeados genericamente de "ecológicos", "sustentáveis" ou "socioambientais" incorporam distintas visões desses conceitos, muitas das quais abarcando diferentes aspectos sociais, conforme o quadro 1.

No ano de 2013, a iniciativa do ICMS Socioambiental, que surge no Paraná, em 1991, é adotada em 15 estados brasileiros. Tem sido um caso emblemático, especialmente na América Latina, a ser replicado como forma de garantir o compromisso de atores locais com políticas de gestão ambiental.

Para o presente trabalho foram comparadas as legislações fiscais dos 15 estados brasileiros apresentados a seguir, no que tange à distribuição do ICMS Socioambiental, analisando sua data de criação, as modificações realizadas, os critérios sociais e ambientais regedores da distribuição do ICMS, além das alíquotas destinadas a cada um desses. 


\section{Discussão teórica}

De forma preambular, algumas considerações se fazem necessárias sobre o referencial teórico que subsidia as conclusões do presente trabalho. Primeiramente, é fundamental uma definição do papel das instituições como objeto de análise. Essa definição nos é dada por O’Donnell (1991:27) e reproduzida a seguir:

Instituições são padrões de interação que são conhecidos, praticados e aceitos regularmente (embora não necessariamente aprovados normativamente) por agentes sociais dados, que, em virtude dessas características, esperam continuar interagindo sob as regras e normas incorporadas (formal ou informalmente) nesses padrões.

Nessa definição de instituições e de seus papéis se encaixam não só as diferentes esferas de um governo como também, de particular relevância para este trabalho, a legislação tributária como instrumento moldador dos "padrões de interação" dos atores envolvidos no processo.

Um segundo aspecto teórico para a presente análise está contido em The tragedy of the commons, de Garret Hardin (1968), que permite compreender a maneira como as instituições vão além de moldar o comportamento dos atores. Através de um exercício teórico, o autor expõe as consequências da interação desregulada entre atores disputando ou usando de maneira concorrente os mesmos recursos naturais, em especial aqueles classificados como bens públicos. ${ }^{2} \mathrm{O}$ exercício especulativo feito por Hardin compara o comportamento dos indivíduos ao processo de "seleção natural" que termina por eliminar aqueles atores preocupados em minimizar seu impacto ambiental, recompensando comportamentos predatórios e ambientalmente irresponsáveis (Hardin, 1968).

O principal aporte desta reflexão teórica é pensar as consequências do comportamento ambientalmente responsável em cenários desregulamentados em que atores econômicos competem por recursos escassos. Esse é o caso dos municípios brasileiros, principalmente em estados que não possuem a legislação do ICMS Socioambiental. Tais municípios buscam maximizar sua parcela na distribuição do orçamento com o objetivo de garantir sua sobrevivência política. Nesse cenário, a menos que haja uma regulação que imponha custos às ações de degradação ambiental, ou que promova alguma forma de compensação àqueles preocupados em internalizar os custos da sustentabilidade, há uma tendência a se criar um cenário de incentivos perversos em que municípios ambientalmente responsáveis tendem a ser progressivamente "eliminados" da competição por recursos.

Em cenários em que há uma ausência de regulação ambiental, os municípios — tomados como atores racionais interessados em maximizar sua parcela na distribuição do orçamento competem diretamente, tanto pelo mesmo orçamento, quanto por muitos dos mesmos recursos

\footnotetext{
${ }^{2}$ Bem público é um bem não rival, não exclusivo e indivisível. Por apresentar tais características, eles são de difícil provisão, uma vez que existem estímulos a um comportamento de free rider daqueles que, conhecendo a sua natureza, esperam receber a sua provisão sem contribuir para a mesma.
} 
naturais. Os líderes municipais comprometidos com a sustentabilidade ambiental, ao restringirem seus processos produtivos (no caso do ICMS, perdendo no quociente de valor agregado, principal critério de distribuição do mesmo), além de reduzirem seu nível de recursos, estariam concomitantemente aumentando o montante de recursos destinado aos demais municípios.

O problema não é a falta de regulação ambiental, mas sim o custo de oportunidade dos recursos (naturais, físicos e humanos) em que os municípios se defrontam. Manter uma Unidade de Conservação (UC), por exemplo, pode trazer sérias restrições econômicas de curto prazo, e essas restrições são ainda maiores quando essa UC é demasiadamente restrita do ponto de vista econômico. O município pode estar mantendo ativos ambientais que podem não ser remunerados em detrimento de convertê-los em ativos econômicos que geram riqueza e bem-estar social; ainda que tragam, eventualmente, custos elevados no longo prazo, não necessariamente haverá concorrentes.

Considerando as limitações da comparação, é fácil entender que atores racionais não reduziriam sua parcela no consumo de certos recursos, uma vez que eles não seriam conservados para seu uso futuro, mas sim consumidos da mesma maneira imediatista por outros atores, seus competidores diretos. Se pensarmos o orçamento como um fator determinante da competição política nos municípios brasileiros, fica claro que os atores preocupados com os custos ambientais de suas ações tenderiam a ser progressivamente eliminados, favorecendo a lógica predatória e irresponsável de consumo desses recursos. Nesse quadro, apenas a regulação feita por agências com poder sobre tais atores poderia impedir esse quadro de incentivos perversos ao consumo dos recursos naturais e de bens públicos — incluindo o orçamento - de maneira irrestrita.

É importante destacar os aspectos econômicos da gestão ambiental, em especial de instrumentos fiscais tais como o ICMS, que tem tido uma abordagem de certa forma distinta por parte da chamada economia ambiental. ${ }^{3}$ Este recorte teórico permite redimensionar a amplitude do problema, incorporando o aspecto do consumo junto ao da produção, o qual vem sendo enfocado até o momento.

Ou seja, mesmo que todas as atividades produtivas humanas respeitassem princípios ecológicos básicos, sua expansão não poderia ultrapassar os limites ambientais que definem a "capacidade de carga” do planeta. Entretanto, como de fato, será muito difícil conhecê-la com precisão; é necessário adotar uma postura proativa, que implica agir sem esperar para ter certeza. (Seiffert, 2010:67)

O principal objetivo dos instrumentos econômicos tem sido o de transferir aos produtores os custos e perdas ocasionados pelas externalidades ambientais negativas aos seus causadores, tanto aqueles envolvidos em seu processo produtivo, quanto aqueles que participam do mesmo como consumidores. Os instrumentos de incentivo econômico à gestão ambiental são inúmeros, cabendo uma série de vantagens e desvantagens a cada um. "Todos esses instrumentos têm como objetivo a mudança de comportamento dos usuários desses recursos, de modo que inclu-

\footnotetext{
${ }^{3}$ Para uma apresentação detalhada dos instrumentos econômicos de gestão ambiental, ver Pereira (2000).
} 
am em seus custos os aspectos ambientais das atividades poluidoras" (Calderoni, 2004 apud Seiffert, 2010:236). Não obstante, alguns comentários merecem ser feitos a respeito dos mecanismos de transferência fiscal, categoria na qual se encaixa o ICMS Socioambiental.

Os mecanismos de transferência fiscal buscam tornar mais próximos os custos ambientais públicos aos dos privados ao fazer com que os atores internalizem os custos da poluição em seus processos produtivos (Seiffert, 2010). A lógica que opera em tais mecanismos é aquela vigente nos impostos e taxas aplicados sobre o produtor gerador da poluição. Estes transferem os custos diretamente para o produtor e também permitem que ele os repasse para os consumidores, dependendo da organização do mercado em que atua. Entretanto, em mercados em que o repasse desses custos aos consumidores é limitado, tais instrumentos podem servir como fortes incentivos para a melhora do desempenho ambiental dos produtores.

O presente recorte teórico ajuda a estabelecer um espectro normativo dentro do qual se podem pensar com mais clareza os problemas e as soluções das questões ambientais, principalmente a partir de uma perspectiva governamental e por meio de mecanismos institucionais. $\mathrm{Na}$ seção seguinte, será focalizada a discussão prática de tais mecanismos de gestão ambiental, o que permite atualizar as variantes locais que assume essa política nos municípios brasileiros.

\section{Pesquisa empírica}

Antes de apresentar os dados dessas comparações, uma descrição da pesquisa empírica assim como alguns comentários preliminares se fazem necessários. É importante destacar a cronologia do surgimento da legislação em questão nesses estados. Grande parte do ônus do processo de aprendizado institucional foi absorvida pelos estados pioneiros na iniciativa (Paraná, São Paulo, Mato Grosso do Sul, Minas Gerais), e pôde ser evitada pelos estados seguidores (Rondônia, Amapá, Rio Grande do Sul, Mato Grosso, Pernambuco, Tocantins, Acre, Rio de Janeiro, Ceará, Piauí, Goiás) por meio de uma análise dos efeitos (desejados e perversos) alcançados nas experiências anteriores.

O quadro 1 permite que visualizemos como se deu a evolução do uso do ICMS como instrumento de gestão ambiental, assim como permite traçar um panorama da situação nacional quanto ao uso desse instrumento e da evolução da preocupação que os governos estaduais vêm demonstrando em face do problema. Para a sua elaboração foi utilizado o ordenamento jurídico vigente nos estados, abarcando o período de 1991 a 2009.

É importante destacar que o presente trabalho tomou como objeto apenas a legislação referente ao ICMS Socioambiental, não considerando a efetividade da sua aplicação. Litígios entre estados e municípios, contestações e disputas políticas quanto aos critérios ambientais para a distribuição desse imposto, entre outros casos particulares em que municípios e estados discordam sobre a melhor maneira de fazer essa distribuição, não são considerados aqui. Parte-se do pressuposto de que, independentemente das especificidades que assume a implementação efetiva dessa legislação, sua análise permite compreender qual o foco das políticas de gestão ambiental dos estados como fruto de um processo de negociação política, assim como explicitar a concepção de sustentabilidade vigente neles, seja por questões ideológicas ou políticas. Tais critérios podem ser encontrados no quadro 1. 
Quadro 1 Critérios do ICMS Socioambiental (Ecológico ou Verde) nos estados brasileiros vigentes em 2010

\begin{tabular}{|c|c|c|c|c|c|c|c|}
\hline \multirow[b]{2}{*}{ Estado } & \multirow{2}{*}{$\begin{array}{c}\text { Ano } \\
\text { da Lei } \\
\text { Original }\end{array}$} & \multirow{2}{*}{$\begin{array}{c}\text { Ano das } \\
\text { Alterações }\end{array}$} & \multicolumn{2}{|c|}{ Critérios Ambientais } & \multicolumn{2}{|l|}{ Critérios Sociais } & \multirow[b]{2}{*}{ Observações } \\
\hline & & & Descrição & $\begin{array}{c}\% \\
\text { (PP)* }\end{array}$ & Descrição & $\%$ (PP)* & \\
\hline \multirow{2}{*}{ PR } & \multirow{2}{*}{1991} & \multirow{2}{*}{$\begin{array}{l}1993 \\
1996 \\
1997 \\
2007\end{array}$} & \begin{tabular}{|l} 
Unidades de \\
conservação
\end{tabular} & $2,5 \%$ & Produção agropecuária & $8 \%$ & \\
\hline & & & $\begin{array}{l}\text { Mananciais de } \\
\text { abastecimento público }\end{array}$ & $2,5 \%$ & Propriedades rurais & $2 \%$ & \\
\hline \multirow[b]{2}{*}{ SP } & \multirow[b]{2}{*}{1993} & & \multirow{2}{*}{$\begin{array}{l}\text { Unidades de } \\
\text { conservação }\end{array}$} & \multirow[b]{2}{*}{$0,5 \%$} & Área cultivada & $3 \%$ & \\
\hline & & & & & $\begin{array}{l}\text { Reservatórios de água destinados } \\
\text { à energia elétrica }\end{array}$ & $0,5 \%$ & \\
\hline \multirow[b]{2}{*}{ MS } & \multirow[b]{2}{*}{1994} & \multirow[b]{2}{*}{$\begin{array}{l}2000 ; \\
2001\end{array}$} & \begin{tabular}{|l} 
Unidades de \\
conservação
\end{tabular} & \multirow[b]{2}{*}{$5 \%$} & & & \multirow{2}{*}{$\begin{array}{l}\text { Aplicação de forma } \\
\text { progressiva durante } \\
\text { o período: 2\% } \\
\text { (2002); 3,5\% } \\
(2003) \text { e } 5 \% \\
(2004) .\end{array}$} \\
\hline & & & $\begin{array}{l}\text { Mananciais de } \\
\text { abastecimento público }\end{array}$ & & & & \\
\hline \multirow{7}{*}{ MG } & \multirow{7}{*}{1995} & \multirow{7}{*}{$\begin{array}{l}2000 \\
2005 \\
2009\end{array}$} & \multirow{4}{*}{$\begin{array}{l}\text { Unidades de } \\
\text { conservação }\end{array}$} & \multirow{4}{*}{$0,5 \%$} & Saúde & $2 \%$ & \\
\hline & & & & & Patrimônio cultural & $1 \%$ & \\
\hline & & & & & Educação & $1 \%$ & \\
\hline & & & & & Área cultivada & $0,5 \%$ & \\
\hline & & & \multirow{3}{*}{$\begin{array}{l}\text { Tratamento resíduos } \\
\text { sólidos }\end{array}$} & \multirow{3}{*}{$0,5 \%$} & $\begin{array}{l}\text { Número de pequenos } \\
\text { produtores rurais }\end{array}$ & $0,25 \%$ & \\
\hline & & & & & Municípios mineradores & $0,11 \%$ & \\
\hline & & & & & $\begin{array}{l}\text { Programa de apoio à produção e } \\
\text { comercialização }\end{array}$ & $0,15 \%$ & \\
\hline RO & 1996 & & $\begin{array}{l}\text { Unidades de } \\
\text { conservação }\end{array}$ & $5 \%$ & & & \\
\hline \multirow{4}{*}{ AP } & \multirow{4}{*}{1996} & & \multirow{4}{*}{$\begin{array}{l}\text { Unidades de } \\
\text { conservação }\end{array}$} & \multirow{4}{*}{$1,4 \%$} & Educação & $2,6 \%$ & \multirow{4}{*}{$\begin{array}{l}\text { Itens progressivos de } \\
1998 \text { a } 2002\end{array}$} \\
\hline & & & & & Área cultivada & $1,4 \%$ & \\
\hline & & & & & Patrimônio cultural & $1,4 \%$ & \\
\hline & & & & & Saúde & $2,60 \%$ & \\
\hline RS & 1997 & $\begin{array}{l}2007 \\
2008\end{array}$ & $\begin{array}{l}\text { Áreas de preservação } \\
\text { ambiental; terras } \\
\text { indígenas e áreas } \\
\text { inundadas por } \\
\text { barragens. }\end{array}$ & $7 \%$ & & & $\begin{array}{l}\text { A porcentagem } \\
\text { é calculada com } \\
\text { base na relação } \\
\text { percentual entre a } \\
\text { área do município, } \\
\text { multiplicando-se } \\
\text { por três as áreas de } \\
\text { proteção ambiental. }\end{array}$ \\
\hline MT & 2000 & $\begin{array}{l}2001 ; \\
2004\end{array}$ & $\begin{array}{l}\text { Unidades de } \\
\text { conservação e terras } \\
\text { indigenas }\end{array}$ & $5 \%$ & Coeficiente social* & $11 \%$ & \begin{tabular}{|l} 
*Corresponde \\
à divisão deste \\
percentual (1 1\%) \\
pela soma do \\
inverso do IDH de \\
todos os municípios \\
existentes \\
no eEstado, \\
multiplicando pelo \\
inverso do IDH de \\
cada município. \\
\end{tabular} \\
\hline
\end{tabular}




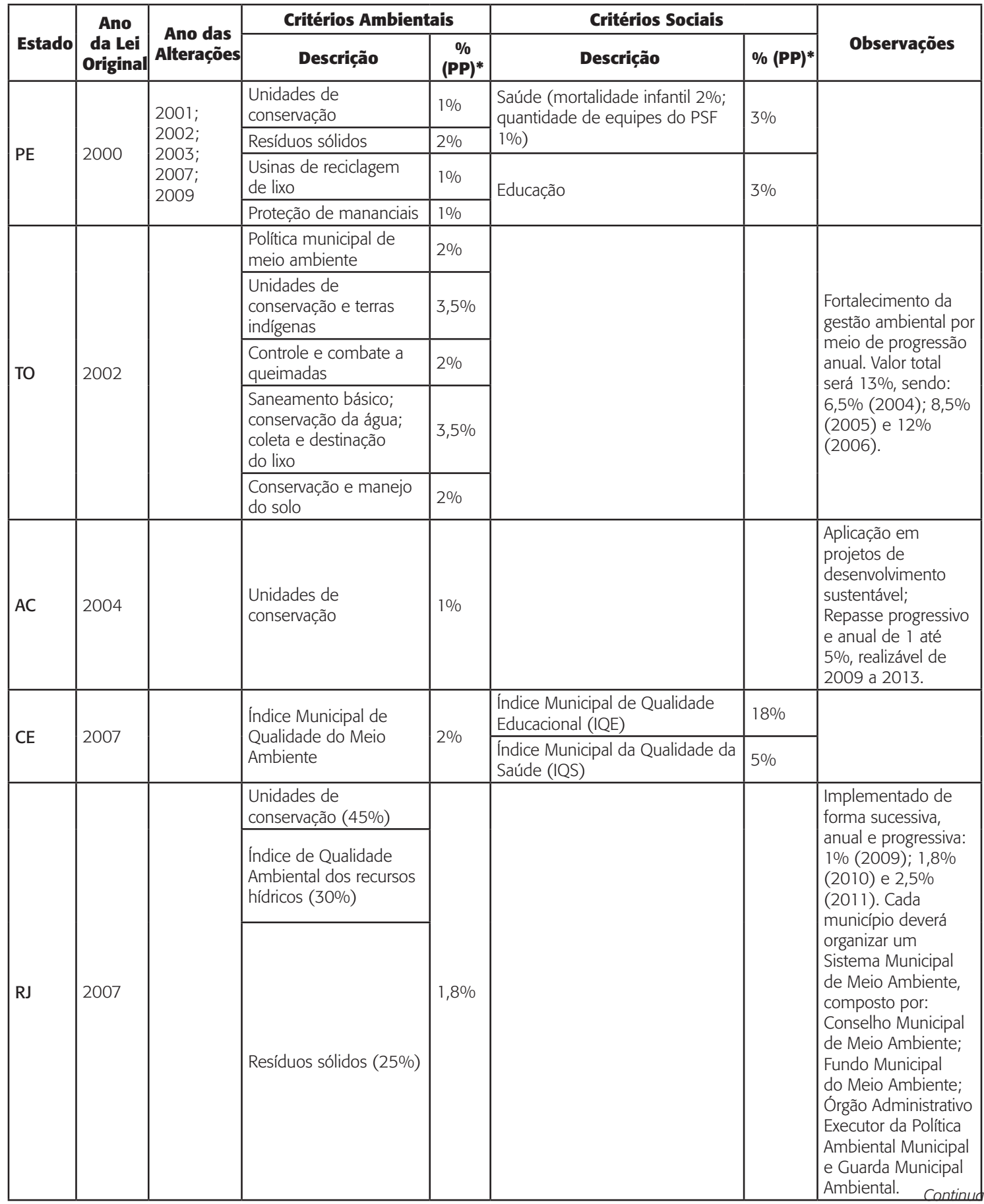




\begin{tabular}{|c|c|c|c|c|c|c|c|}
\hline \multirow[b]{2}{*}{ Estado } & \multirow{2}{*}{$\begin{array}{c}\text { Ano } \\
\text { da Lei } \\
\text { Original }\end{array}$} & \multirow{2}{*}{$\begin{array}{c}\text { Ano das } \\
\text { Alterações }\end{array}$} & \multicolumn{2}{|c|}{ Critérios Ambientais } & \multicolumn{2}{|c|}{ Critérios Sociais } & \multirow[b]{2}{*}{ Observações } \\
\hline & & & Descrição & $\begin{array}{c}\% \\
\text { (PP)* }\end{array}$ & Descrição & $\%$ (PP)* & \\
\hline GO & 2007 & & $\begin{array}{l}\text { Fiscalização, defesa, } \\
\text { recuperação e } \\
\text { preservação do meio } \\
\text { ambiente }\end{array}$ & $0 \%$ & & & $\begin{array}{l}\text { O Estado ainda } \\
\text { não regulamentou } \\
\text { a Emenda } \\
\text { Constitucional } \\
\text { no } 40 \text {, de } 30 \text { de } \\
\text { maio de } 2007 \text {, que } \\
\text { instituiu o ICMS } \\
\text { Socioambiental. O } \\
\text { percentual destinado } \\
\text { seria de } 5 \% \text {. }\end{array}$ \\
\hline $\mathrm{PI}$ & 2008 & & $\begin{array}{l}\text { Fortalecimento da } \\
\text { gestão ambiental - Selo } \\
\text { Ambiental (categorias } \\
\text { A; B; C). }\end{array}$ & $3 \%$ & & & $\begin{array}{l}\text { Forma progressiva } \\
\text { anual para cada } \\
\text { categoria. } \\
\text { - 1,5\% em 2009, } \\
\text { sendo: 0,07\% } \\
\text { categoria A; 0,05\% } \\
\text { categoria B e 0,03\% } \\
\text { categoria C; } \\
\text { - 3\% em } 2010, \\
\text { sendo: } 1,3 \%(A) ; \\
1 \%(B) ; 0,7 \%(C) ; \\
\text { - 5\% em } 2011 \text {, } \\
\text { sendo: } 2 \%(A) ; \\
1,65 \%(B) \text { e 1,35\% } \\
\text { (C). }\end{array}$ \\
\hline
\end{tabular}

Fonte: Legislações estaduais.

Elaboração da autora.

PP*: Pontos percentuais 
A partir das experiências dos estados onde o ICMS Socioambiental está em pleno funcionamento, pode-se perceber o crescimento do estímulo aos municípios para criarem ou defenderem a criação de alguns componentes ambientais importantes, como espaços especialmente protegidos, aterros sanitários e, em alguns casos específicos, políticas de controle e combate de queimadas, conservação dos solos e conservação da água.

\section{O ICMS Socioambiental em perspectiva comparada}

O uso do ICMS como instrumento econômico de gestão ambiental teve início, no Brasil, no estado do Paraná, conforme mencionado. A particularidade do surgimento desse instrumento está no fato de ele ter surgido da necessidade autêntica dos municípios desse estado em encontrar fontes alternativas de financiamento, alternativas às políticas pontuais de preservação ambiental que, no Brasil, costumam ter origem nas esferas mais altas do Estado, na sua maioria de caráter federal. É importante ressaltar que esse fato é potencializado dado que os recursos do ICMS Socioambiental são repassados aos municípios, cabendo a eles a decisão sobre como alocar tais valores. A liberdade em definir os destinos das verbas arrecadadas por meio do tributo serve como incentivo adicional para os gestores municipais coincidirem os requisitos ambientais para acessar esses recursos.

A criação a partir da base foi o aspecto de extrema importância para o êxito do ICMS Socioambiental como uma política pública replicável em outros estados brasileiros, figurando hoje como um dos principais instrumentos econômicos de gestão ambiental em nível municipal. A reivindicação de novos critérios de distribuição do tributo surgiu justamente dos municípios paranaenses que, por abrigarem áreas de preservação ambiental, assim como mananciais de abastecimento, se viam numa situação claramente desfavorável devido ao critério majoritário de distribuição do ICMS que era o valor adicionado gerado pelo município (Tupiassu, 2006; Loureiro, 1997).

Pouco tempo após a iniciativa paranaense, outros estados também adaptaram suas legislações, de maneira a incluir critérios ambientais na distribuição do ICMS aos municípios. Esses estados foram São Paulo, Mato Grosso do Sul e Minas Gerais, "estados pioneiros” do ICMS Socioambiental. Alguns comentários merecem ser feitos sobre cada uma dessas experiências.

O caso paulista se destaca por uma aparente contradição: apesar de incluir diversos elementos em seus critérios de distribuição ambiental, o estado destina para eles uma porcentagem ínfima do seu ICMS (0,5\%). Já outros critérios apresentam um percentual maior, em especial a extensão de áreas cultivadas, que tem a alíquota de 3\%. Não obstante, nota-se que tal critério possui um viés muito mais econômico do que ambiental. Pode-se defender as baixas alíquotas destinadas aos critérios ambientais pelo fato de o estado possuir a maior arrecadação do imposto. Entretanto, se comparada às demais alíquotas do próprio estado, fica clara a menor importância dada às questões ambientais relativamente a outros fatores mais politicamente relevantes.

O Mato Grosso do Sul é um dos estados em que o ICMS assume seu caráter mais puramente "Ecológico" ou comprometido com a preservação ambiental. O estado destina 5\% 
da distribuição do imposto apenas para critério ambiental, não incluindo aspectos sociais na distribuição dessa parte do tributo. Isso também remete a uma concepção mais restrita de sustentabilidade presente na legislação do estado, restringindo seu critério de distribuição a fatores estritamente ambientais.

Uma observação que merece ser feita sobre a legislação sul-mato-grossense é o caráter progressivo incorporado à implementação da legislação. Essa progressividade consistiu em adotar alíquotas de 2\%, 3,5\% e 5\% nos três primeiros anos da nova legislação, permitindo que houvesse uma melhor acomodação dos interesses políticos afetados, uma maior aceitação da nova legislação por parte daqueles atores que tiveram interesses contrariados e, finalmente, que os municípios pudessem reorganizar-se segundo as novas "regras do jogo".

O exemplo de Minas Gerais é, em grande parte, similar ao paulista. Ainda que incorporando diversos critérios ambientais para a distribuição do ICMS, a legislação mineira destina alíquotas bastante reduzidas para cada um deles. Novamente destaca-se o volume da arrecadação desses estados como fator atenuante das menores alíquotas. Entretanto, em Minas Gerais, esse fator esbarra no número de 853 municípios que possui o estado, o que contribui ainda mais para diluir os incentivos ecológicos do ICMS. Por outro lado, de maneira ainda mais pronunciada que São Paulo, o estado tem inúmeras alíquotas sociais para a distribuição do tributo, as quais compartilham um volume de recursos consideravelmente maior do que as ambientais. Isso nos permite visualizar a distribuição de prioridades da administração mineira.

Os demais estados que aprenderam das experiências anteriores também apresentam alguns casos interessantes, entre os quais o Mato Grosso e o Ceará. O estado do Mato Grosso apresenta um indicador ousado em termos de política estadual que é a alocação de $11 \%$ da distribuição do orçamento para o chamado "coeficiente social", que corresponde a uma medida baseada no Índice de Desenvolvimento Humano (IDH) dos municípios do estado. Nessa mesma linha, o Ceará se destaca por apresentar um forte incentivo à educação, destinando $18 \%$ do repasse do ICMS estadual de acordo com os resultados do Índice Municipal de Educação, além de distribuir mais 5\% do imposto de acordo com o Índice Municipal da Qualidade da Saúde. Os demais estados se repetem tanto em termos dos critérios de distribuição, assim como nas alíquotas destinadas aos mesmos.

Convencionou-se referir-se a estados "pioneiros" e estados "seguidores" em relação ao ICMS Socioambiental ou Ecológico, estando incluídos em cada um desses grupos os estados já mencionados. Entretanto, considerando-se aspectos normativos, pode-se classificá-los em duas gerações de legislação sobre os critérios ambientais de distribuição do ICMS. A primeira, da década de 1990, coincide em grande medida com os "estados pioneiros", com o acréscimo apenas de Rondônia, Amapá e Rio Grande do Sul. A segunda é a que surge a partir do ano 2000 após a publicação da Lei no 9.985, de 18 de julho de $2000,{ }^{4}$ que traz um cenário normativo distinto no que se refere à regulação dos critérios ambientais do ICMS.

\footnotetext{
${ }^{4}$ Esta Lei institui o Sistema Nacional de Unidades de Conservação da Natureza (Snuc), estabelece critérios e normas para a criação, implantação e gestão das unidades de conservação.
} 
As unidades de conservação passaram a ser o principal objeto do incentivo proposto pelo ICMS Socioambiental em diversos "estados seguidores". A inclusão das unidades de conservação como objetivo da distribuição do ICMS também foi o motivo de algumas das reformas ocorridas nos estados "pioneiros" ou da primeira geração da política. Essa divisão em duas gerações de legislação sobre a distribuição do tributo, assim como uma análise mais detida na evolução global dos objetos do ICMS nos diversos estados brasileiros ensejam algumas conclusões mais gerais sobre a evolução dos critérios de distribuição do mesmo.

Primeiramente, é importante destacar uma distinção básica entre os critérios ambientais e sociais utilizados na distribuição do ICMS. Ainda que uma concepção holística de sustentabilidade compreenda as duas categorias, que serão discutidas a seguir. ${ }^{5}$ Critérios ambientais para a distribuição do imposto variam principalmente entre unidades de conservação, terras indígenas, tratamento de resíduos sólidos, além de índices estaduais de gestão ambiental que incorporam tais fatores. Os critérios sociais adotados tenderam, por sua vez, a incluir virtualmente todas as áreas de administração pública, favorecendo principalmente os serviços de primeira necessidade.

Outro aspecto importante, que derivou em grande parte do aprendizado que estados seguidores puderam ter com as experiências iniciais do ICMS Socioambiental, diz respeito à aplicação progressiva das novas fórmulas de distribuição do tributo. Isso criou um incentivo a mais para a conservação ambiental, na medida em que proporcionou um tempo de ajuste aos municípios para se adequar a esses novos critérios de distribuição, em especial no que diz respeito a questões de preservação ambiental, onde os municípios dispõem de uma margem de ação um pouco mais ampla.

\section{Incentivos econômicos e variantes institucionais}

Conforme pôde ser observado no quadro 1, os estados brasileiros adotam concepções diferentes da maneira como deve funcionar a distribuição do ICMS como incentivo a práticas de preservação ambiental. Nesse sentido, o principal fator que varia entre esses estados é a porcentagem da alíquota destinada a estimular essas práticas. Enquanto alguns estados acreditam em um modelo que promova benefícios concentrados, outros adotam uma distribuição difusa dos incentivos a essas práticas.

O nível de concentração desses benefícios passa por duas variáveis. A primeira é o montante de recursos destinado aos repasses ambientais. Convém notar que a porcentagem, ainda que seja um comparativo interessante, pode apresentar um determinado viés de análise devido à grande discrepância entre a arrecadação de diferentes estados. Isso quer dizer que o ponto percentual de recursos do ICMS do estado de São Paulo não é diretamente comparável

\footnotetext{
${ }^{5}$ Essa concepção holística reflete o uso alternado das adjetivações: Verde, Ecológico e Socioambiental para qualificar o ICMS como sinônimas.
} 
a esse mesmo ponto percentual na distribuição do ICMS do estado do Piauí. Não obstante, a porcentagem nos indica a priorização dos critérios ambientais dentro de um mesmo estado.

A segunda forma de concentração desses benefícios diz respeito às ações de preservação ambiental que entram na contabilização do montante de recursos a ser repassado. Enquanto alguns estados se limitam a ações específicas, normalmente condizentes com o plano de gestão ambiental do estado, outros pulverizam esse incentivo, contabilizando inúmeras ações para o repasse do tributo gerando sistemas onde o incentivo do ICMS é neutralizado diante do custo de oportunidade de outras opções econômicas de emprego da terra e dos recursos naturais.

Alguns estados merecem uma atenção particular, ao corroborar a importância da concentração dos incentivos na definição de quais os critérios que devem ser seguidos na elaboração normativa das alíquotas e dos critérios de distribuição do ICMS Socioambiental. Nele é destacado o caso das Unidades de Conservação que, quando devidamente protegidas, apresentam uma correlação positiva com o uso do ICMS Socioambiental.

Os determinantes político-institucionais dos diferentes estados brasileiros também são essenciais para explicar os diferentes critérios sociais que são incorporados à distribuição do ICMS. É importante que sejam adotados critérios sociais para tornar a distribuição do imposto progressiva, assim como para abranger um maior número de municípios, incorporando a heterogeneidade inerente aos mesmos. Entretanto, se são ampliados fatores em demasia, o incentivo é pulverizado e não se torna atraente em face de outras atividades econômicas, em especial perante o valor fiscal adicionado, principal critério de distribuição do ICMS.

É importante destacar que os critérios que devem ser enfatizados para a distribuição do ICMS Socioambiental devem ser aqueles de responsabilidade municipal. Entre eles se destacam as Unidades de Conservação, uma vez que diversos outros critérios de distribuição do tributo são determinados por aspectos que se encontram além da esfera de ação municipal, fazendo com que, ainda que importantes, não atuem como incentivos diretos à preservação ambiental.

$\mathrm{O}$ aspecto temporal também é importante quando se refere a incentivos institucionais. Mecanismos como as novas fórmulas de distribuição do ICMS não podem ser destacados do contexto político em que surgem e no qual estão inseridos. Nesse sentido, as experiências estudadas até agora mostram que fórmulas progressivas de implementação das novas alíquotas de distribuição do ICMS permitem transições mais seguras, diminuindo o impacto de interesses e conflitos políticos que podem desgastar o apoio político-institucional à nova distribuição.

Seguindo a mesma linha argumentativa, um segundo fato chama a atenção para a complexidade da institucionalização desse tipo de incentivo econômico, em especial na interação provocada entre distintas esferas do governo e para as particularidades regionais que assumem a promoção de uma mesma política em diferentes regiões do Brasil. Como é demonstrado por pesquisas recentes, ${ }^{6}$ aspectos simples como o acesso à informação sobre o

\footnotetext{
${ }^{6}$ Ring (2008:485-497). Trata-se de um artigo da pesquisadora Irene Ring, da Universidade Leipzig, Alemanha, tratando do ICMS Socioambiental em relação a programas fiscais de outros países, a exemplo da Alemanha e do Panamá.
} 
incentivo econômico do ICMS Socioambiental podem ser barreiras para alcançar os objetivos da política. Isso se mostrou relevante principalmente em municípios no Nordeste brasileiro, como é o caso do estado de Pernambuco (Pernambuco, 2006).

Nesse sentido, a elaboração de tais instrumentos normativos por parte dos legislativos estaduais deve ser acompanhada de ações afirmativas concomitantes que vão desde a difusão da informação e a publicação da nova lei, até parcerias intergovernamentais que promovam apoio técnico e conscientização dos atores envolvidos da importância de tais medidas. Uma abordagem mais holisticamente orientada, especialmente considerando as particularidades estaduais do tipo de preservação que encabeça a lista de prioridades do estado, é essencial para a consolidação efetiva desses incentivos. Novamente, nunca é demais reiterar que, ainda que sejam importantes mecanismos redistributivos, tal como o ICMS Socioambiental, não podem ser considerados como a solução dos problemas ambientais estaduais.

Outro fator que merece destaque é que haja um compromisso político explícito com a perenidade desses incentivos. Incentivos tidos como frágeis e passíveis de constantes modificações, ou ainda aqueles encarados como políticas de governo serão tomados pelos gestores municipais como pouco atrativos, em especial para os gestores municipais comprometidos com uma gestão orientada com o longo prazo, que tendem a ser os mesmos que apoiam as medidas de preservação e conservação ambiental.

Para tanto devem ser pensados instrumentos normativos complementares, que não só promovam incentivos para sua manutenção, mas que imponham custos para sua modificação por meio da inércia institucional que surge do comprometimento de vários atores com um determinado arranjo institucional. Para o funcionamento desse arranjo institucional são necessários atores municipais que dependam e contem com os recursos destinados ao ICMS Socioambiental, uma sociedade civil que entenda e exija o respeito às questões ambientais, além de um arranjo jurídico que proteja os atores envolvidos nesse processo. Afinal, o grande problema é que a transferência dos recursos não tem segurança de ser aplicada na gestão ambiental, daí a importância do controle social desses gastos.

\section{Considerações finais}

A análise dos aspectos jurídico-institucionais do ICMS Socioambiental brasileiro conduz a breves conclusões. Primeiramente, cabe destacar que, apesar do seu êxito reiteradamente mencionado e do potencial desse instrumento econômico de gestão ambiental, ele deve ser analisado como um mecanismo dentro de uma política mais ampla de preservação ambiental, que vai além dos mecanismos de comando e controle. É extremamente importante que os estados não usem o ICMS como a solução de todos os seus problemas ambientais, deixando a gestão dos mesmos unicamente nas mãos dos gestores municipais. Esse mecanismo deve ser complementar a uma estratégia mais ampla que tenha claras definições de prioridades estaduais e mecanismos de gestão ambiental. 
Se aplicado de maneira responsável e não apenas como uma forma de transferir responsabilidades aos atores municipais, desvinculando os estados de suas responsabilidades complementares, o ICMS Socioambiental pode ser um instrumento valioso para promover políticas de preservação ambiental. É especialmente relevante por comprometer os gestores municipais com essas ações garantindo assim sua maior efetividade. "A tributação se por um lado visa ao financiamento do Estado (...) também se presta ao papel de instrumento de política social e econômica, isto é, um instrumento de promoção da cidadania" (Vieira, 1995:72). Conforme mencionado, estudos demonstraram que o ICMS tem funcionado como incentivo à criação de Unidades de Conservação, além de outras ações de conservação do meio ambiente por parte dos municípios.

As questões ambientais têm obtido cada vez mais relevância nas últimas décadas. Elas têm se intensificado em razão do crescimento populacional e da concentração cada vez maior da população nos centros urbanos. Por sua multiplicidade e mutação constante, os problemas ambientais podem ser mais bem enfrentados pelos atores locais, especialmente quando estes têm os incentivos corretos para fazê-lo. Portanto, espera-se que haja uma consolidação do ICMS Socioambiental como um instrumento perene e que o mesmo seja pautado por objetivos de longo prazo, fortalecendo assim a gestão ambiental no Brasil responsável e sustentável do ponto de vista político, assim como econômico.

Com esse objetivo, o estudo mais aprofundado e sistemático das técnicas de gestão ambiental se faz cada vez mais urgente, uma vez que as ações governamentais precisam de subsídios empíricos para a tomada de decisão. Entretanto, é preciso sempre ter em mente que "esses grupos de instrumentos de gestão ambiental apresentam uma função complementar no processo de gestão ambiental, não existindo uma configuração predefinida que possa ser recomendada" (Seiffert, 2010:298), devendo, portanto, ser estimulada a autonomia local — mais apta a lidar com as especificidades dos problemas ambientais - desde que amparada pelo compromisso nacional com a preservação do meio ambiente.

Não obstante, há ameaças no horizonte. Uma é extinguir a discricionariedade sobre os 25\% que resultariam da federalização do ICMS. A outra seria limitar o critério de repartição ao critério do valor adicionado fiscal. Representantes dos estados têm se oposto a essas medidas no Congresso Nacional onde se encontram propostas nesse sentido (Jatobá e Sobreira de Moura, 2009). O ICMS Socioambiental é hoje um dos poucos instrumentos econômicos vigentes a incorporar na gestão de recursos ambientais o princípio protetor-recebedor (em oposição ao princípio poluidor pagador mais intensamente utilizado no Brasil), representando uma mudança de postura que vem sendo assumida pelo Estado brasileiro, de considerar o valor inestimável e insubstituível dos recursos ambientais, devendo sua proteção ser objeto prioritário das políticas nacionais.

A globalização também coloca uma série de desafios a uma gestão ambiental efetiva. A globalização não pode ser pensada sem uma economia global, com atores e problemas que atuam nessa mesma escala. Conseguir impor uma regulação efetiva em escala global tem sido um dos principais desafios contemporâneos para uma gestão ambiental efetiva (Seiffert, 2010). O desmantelamento da capacidade dos estados, principalmente os menores, de fazer 
frente aos grandes grupos econômicos transnacionais, assim como de ter a capacidade de atuar em problemas sistêmicos em nível global, exige uma nova maneira de se abordar a questão da regulação ambiental (Müller, 2001).

Esse cenário tem levado a uma estratégia de certa maneira paradoxal, mas que tem se mostrado bastante efetiva, que é o empoderamento dos atores locais no processo de regulação ambiental. Isso se deve ao fato de que esses atores têm maior interesse em lidar com seus problemas ambientais em suas especificidades locais. Não obstante, frequentemente tais iniciativas encontram entraves nos interesses de grupos tanto domésticos quanto internacionais. Para que de fato alcancem seus objetivos é necessário um passo adiante na neutralização dos grupos desinteressados nas políticas de conservação ambiental que têm ganhado forças no Brasil (Donaire, 1999).

Por último, vale lembrar "o instrumento dos instrumentos de gestão ambiental, em virtude de ser o pressuposto básico para a implementação da maioria dos outros instrumentos", que é a educação ambiental (Seiffert, 2010:299). Não se pode esperar que haja um compromisso de atores tanto governamentais quanto privados com uma gestão ambiental responsável e sustentável, caso os mesmos não estejam convencidos da sua. A educação ambiental deve ser incorporada como projeto de sociedade tanto relativamente às grandes questões nacionais, quanto em questões rotineiras dos cidadãos. É necessário que diversas esferas atuem em conjunto de maneira a se fortalecerem rumo a um projeto de sociedade sustentável que respeite e proteja a diversidade. Somente então será possível almejar um projeto de sociedade sustentável voltada para objetivos de longo prazo.

\section{Referências}

ACRE. Lei no 1.530, de 22 de janeiro de 2004. Institui o ICMS verde, destinando 5\% da arrecadação deste tributo para os municípios com unidades de conservação ambiental. Diário Oficial do Estado do Acre, Rio Branco, 22 jan. 2004.

AMAPÁ. Lei no 322, de 23 de dezembro de 1996. Dispõe sobre a distribuição da parcela da receita do produto da arrecadação dos impostos estaduais conforme disposições contidas no artigo 158 da Constituição Federal e Lei Complementar Federal oㅡ 63/90, e dá outras providências. Diário Oficial do Estado do Amapá, Macapá, 23 dez. 1996.

BACHA, Carlos José C.; SHIKIDA, Pery Francisco A. Experiências brasileiras na implementação do ICMS Ecológico. In: CASIMIRO FILHO, Francisco; SHIKIDA, Pery Francisco A. (Org.). Agronegócio e desenvolvimento regional. Cascavel: Edunices, 1999. p. 179-207.

BRASIL. Constituição Federal. Constituição da República Federativa do Brasil. Brasília, DF: Senado, 1988.

CALDERONI, Sabetai. Economia ambiental. In: PHILLIPI JR., Arlindo; ROMÉRO, Marcelo de A.; BRUNA, Gilda C. Curso de gestão ambiental. Barueri: Manole, 2004. p. 571-616. 
CEARÁ. Lei no 14.023, de 17 de dezembro de 2007. Modifica dispositivos da Lei no 12.612, de 7 de agosto de 1996, que define critérios para distribuição da parcela de receita do produto e arrecadação do Imposto sobre Operações Relativas à Circulação de Mercadorias e sobre Prestações de Serviços de Transporte Interestadual e Intermunicipal e de Comunicação - ICMS, pertencente aos municípios e dá outras providências. Diário Oficial do Estado do Ceará, Fortaleza, 17 dez. 2007.

DONAIRE, Denis. Gestão ambiental na empresa. 2. ed. São Paulo: Atlas, 1999.

GOIÁS. Emenda Constitucional nº 40, de 30 de maio de 2007.

HARDIN, Garret. The tragedy of the commons. Science, v. 162, n. 3859, p. 1243-12-48, dez. 1968.

JATOBÁ, Jorge. O ICMS como instrumento econômico para a gestão ambiental. Santiago de Chile: Cepal, 2003.

JATOBÁ, Jorge; SOBREIRA DE MOURA, Alexandrina. Federalismo ambiental no Brasil. In: SOBREIRA DE MOURA, Alexandrina. Políticas públicas e meio ambiente: da economia política às ações setoriais. Recife: Massangana, 2009. p. 45-105.

LOUREIRO, Wilson. ICMS Ecológico; incentivo econômico à conservação da biodiversidade: uma experiência exitosa no Brasil. Revista de Administração Municipal, v. 44, n. 221, p. 49-60, abr./dez. 1997.

MATO GROSSO. Decreto ํㅡㄹ 2.758 de 16 de julho de 2001. Regulamenta o artigo 8o da Lei Complementar ํㅡ 73, de 07 de dezembro de 2000, seus anexos e dá outras providências. Diário Oficial do Estado do Mato Grosso, Cuiabá, 16 jul. 2001.

MATO GROSSO. Lei Complementar no 73 de 7 de dezembro de 2000. Dispõe sobre os critérios de distribuição da parcela de receita do ICMS pertencente aos Municípios, de que tratam os incisos I e II do parágrafo único do art. 157 da Constituição Estadual e dá outras providências. Diário Oficial do Estado do Mato Grosso, Cuiabá, 7 dez. 2003.

MATO GROSSO. Lei Complementar no 157 de 20 de janeiro de 2004. Estabelece normas relativas ao cálculo dos Índices de Participação dos Municípios do Estado de Mato Grosso no produto da arrecadação do ICMS, e dá outras providências. Diário Oficial do Estado do Mato Grosso, Cuiabá, 20 jan. 2004.

MATO GROSSO DO SUL. Lei Complementar no 77 de 7 de dezembro de 1994. Altera a redação de dispositivo da Lei Complementar no 57 , de 4 de janeiro de 1991, e dá outras providências. Diário Oficial do Estado do Mato Grosso do Sul, Mato Grosso do Sul, Campo Grande, 7 dez. 1994.

MATO GROSSO DO SUL. Lei no 2.193 de 18 de dezembro de 2000. Dispõe sobre o ICMS ECOLÓGICO, na forma do art. 1ํㅡㄴ, III, alínea "f" da Lei Complementar no 57, de 4 de janeiro de 1991, com redação dada pela Lei Complementar no 77, de 7 de dezembro de 1994, e dá outras providências. Diário Oficial do Estado do Mato Grosso do Sul, Campo Grande, 18 dez. 2000.

MATO GROSSO DO SUL. Portaria no 1 de 3 de setembro de 2001. Regula os procedimentos administrativos para organização do Cadastro do Sistema Estadual de Unidades de Conservação, a operacionalização dos cálculos, a gestão e a democratização das informações do Programa Estadual 
do ICMS Ecológico, e dá outras providências. Diário Oficial do Estado do Mato Grosso do Sul, Campo Grande, 3 set. 2001.

MINAS GERAIS. Deliberação Normativa Copam n 86, de 17 de junho de 2005. Estabelece normas para o licenciamento ambiental de loteamentos do solo urbano para fins exclusiva ou predominantemente residenciais, e dá outras providências. Diário Oficial do Estado de Minas Gerais, Belo Horizonte, 17 jun. 2005.

MINAS GERAIS. Lei no 12.040 , de 28 de dezembro de 1995. Dispõe sobre a distribuição da parcela de receita do produto da arrecadação do ICMS pertencente aos Municípios, de que trata o inciso II do parágrafo único do artigo 158 da Constituição Federal, e dá outras providências. Diário Oficial do Estado de Minas Gerais, Belo Horizonte, 29 dez. 1995.

MINAS GERAIS. Lei no 13.803, de 27 de dezembro de 2000. Dispõe sobre a distribuição da parcela da receita do produto da arrecadação do ICMS pertencente aos municípios. Diário Oficial do Estado de Minas Gerais, Belo Horizonte, 27 dez. 2000.

MINAS GERAIS. Lei no 18.030, de 12 de janeiro de 2009. Dispõe sobre a distribuição da parcela da receita do produto da Arrecadação do ICMS pertencente aos municípios. Diário Oficial do Estado de Minas Gerais, Belo Horizonte, 12 jan. 2009.

MÜLLER, Geraldo. Desenvolvimento sustentável: notas para a elaboração de um esquema de referência. In: BECKER, Dinizar F. (Org.). Desenvolvimento sustentável: necessidade e/ou possibilidade? 3. ed. Santa Cruz do Sul: Edunisc, 2001. p. 117-138.

O’DONNELL, Guillermo. Democracia delegativa? Novos Estudos Cebrap, n. 31, p. 25-40, out. 1991.

PARANÁ. Decreto Estadual no 1.529, de 2 de outubro de 2007. Dispõe sobre o Estatuto Estadual de Apoio à Conservação da Biodiversidade em Terras Privadas no Estado do Paraná, atualiza procedimentos para a criação de Reservas Particulares do Patrimônio Natural — RPPN. Diário Oficial do Estado do Paraná, Curitiba, 2 out. 2007.

PARANÁ. Decreto no 2.791, de 27 de dezembro de 1996. Estabelece os critérios técnicos de alocação de recursos a que alude o art. 5o da Lei Complementar no 59, de 01 de outubro de 1991, relativos a mananciais destinados a abastecimento público e unidades de conservação. Diário Oficial do Estado do Paraná, Curitiba, 27 dez. 1996.

PARANÁ. Decreto no 3.446, de 14 de agosto de 1997. Criadas no Estado do Paraná as Áreas Especiais de Uso Regulamentado - Aresur. Diário Oficial do Estado do Paraná, Curitiba, 14 ago. 1997.

PARANÁ. Lei Complementar no 59, de 1 de outubro de 1991. Dispõe sobre a repartição de 5\% do ICMS, a que alude o art. $2^{\circ}$ da Lei 9.491/90, aos municípios com mananciais de abastecimento e unidades de conservação ambiental, assim como adota outras providências. Diário Oficial do Estado do Paraná, Curitiba, 1ํo out. 1991. 
PARANÁ. Lei Complementar nº 67, de 08 de janeiro de 1993. Dá nova redação ao art. 2º da Lei Complementar n 59, de 1ํde outubro de 1991. Diário Oficial do Estado do Paraná, Curitiba, 8 jan. 1993.

PARANÁ. Lei no 9.491, de 21 de dezembro de 1990. Estabelece critérios para fixação dos índices de participação dos Municípios no produto da arrecadação do ICMS. Diário Oficial do Estado do Paraná, Curitiba, 21 dez. 1990.

PARANÁ. Lei no 12.417 de 30 de dezembro de 1998. Dá nova redação ao inciso III, do art. 1o, da Lei no 9.941, de 21 de dezembro de 1990. Diário Oficial do Estado do Paraná, Curitiba, 30 dez. 1998.

PEREIRA, Paulo Affonso S. Rios, redes e regiões: a sustentabilidade a partir de um enfoque integrado dos recursos terrestres. Porto Alegre: AGE, 2000.

PERNAMBUCO. Decreto no 23.473 de 10 de agosto de 2001. Regulamenta os critérios de distribuição da parcela do ICMS que cabe aos Municípios, relativos aos aspectos socioambientais de que trata o inciso III do artigo $2^{\circ}$ da Lei no 10.489, de 2 de outubro de 1990, com a redação conferida pela Lei no 11.899, de 21 de dezembro de 2000, e dá outras providências. Diário Oficial do Estado do Pernambuco, Recife, 10 ago. 2001.

PERNAMBUCO. Lei no 11.899 de 21 de dezembro de 2000. Redefine os critérios de distribuição da parte do ICMS que cabe aos municípios, de que trata o artigo $2^{\circ}$, da Lei no 10.489 , de 2 de outubro de 1990, considerando aspectos socioambientais, e dá outras providências. Diário Oficial do Estado do Pernambuco, Recife, 21 dez. 2000.

PERNAMBUCO. Lei no 12.206 de 21 de dezembro de 2002. Ajusta os critérios de distribuição de parte do ICMS que cabe aos Municípios, nos termos do art. 2º, da Lei ํㅜ 10.489, de 2 de outubro de 1990, com a redação da Lei no 11.899, de 21 de dezembro de 2000, relativamente aos aspectos socioambientais. Diário Oficial do Estado do Pernambuco, Recife, 21 dez. 2002.

PERNAMBUCO. Lei no 12.432, de 29 de setembro de 2003. Ajusta os critérios de distribuição de parte do ICMS que cabe aos Municípios, nos termos do art. 2º, da Lei no 10.489 , de 2 de outubro de 1990, coma redação da Lei no 11.899, de 21 de dezembro de 2000, e da Lei no 12.206, de 20 de maio de 2002. Diário Oficial do Estado do Pernambuco, Recife, 29 set. 2003.

PERNAMBUCO. Lei no 13.368 de 14 de dezembro de 2007. Ajusta critérios de distribuição de parte do ICMS que cabe aos Municípios, nos termos da Lei no 10.489, de 2 de outubro de 1990, e alterações. Diário Oficial do Estado do Pernambuco, Recife, 14 dez. 2007.

PERNAMBUCO. Lei ㄲo 13.931 de 3 de dezembro de 2009. Introduz modificações na Lei no 10.489, de 2 de outubro de 1990, e alterações, relativamente a redefinições de critérios de distribuição de parte do ICMS que cabe aos Municípios. Diário Oficial do Estado do Pernambuco, Recife, 4 dez. 2009.

PERNAMBUCO. Secretaria de Ciência, Tecnologia e Meio Ambiente. ICMS socioambiental: a experiência do Estado de Pernambuco. Recife: Sectma, 2006. 
PIAUÍ. Lei no 5.813, de 3 de dezembro de 2008. Cria o ICMS Ecológico para beneficiar municípios que se destaquem na proteção ao meio ambiente e dá outras providências. Diário Oficial do Estado do Piauí, Teresina, 3 dez. 2008.

RING, Irene. Integrating local ecological services into intergovernmental fiscal transfers: the case of the ecological ICMS in Brazil. Land Use Policy, Adelaide, n. 25, p. 485-497, 2008.

RIO DE JANEIRO. Lei no 5.100, de 4 de outubro de 2007. Altera a Lei no 2.664, de dezembro de 1996, que trata da repartição aos municípios da parcela de $25 \%$ (vinte e cinco por cento) do produto da arrecadação do ICMS, incluindo o critério de conservação ambiental, e dá outras providências. Diário Oficial do Estado do Rio de Janeiro, Rio de Janeiro, 4 out. 2007.

RIO GRANDE DO SUL. Lei no 11.038 , de 14 de novembro de 1997 . Dispõe sobre a parcela do produto da arrecadação do Imposto sobre Operações Relativas à Circulação de Mercadorias e sobre Prestações de Serviços de Transporte Interestadual e Intermunicipal e de Comunicação (ICMS) pertencente aos municípios. Diário Oficial do Estado do Rio Grande do Sul, Porto Alegre, 14 nov. 1997.

RONDÔNIA. Lei Complementar no 147, de 15 de janeiro de 1996. Altera e acrescenta dispositivos à Lei Complementar no 115, de 14 de junho de 1994, e dá outras providências. Diário Oficial do Estado de Rondônia, Porto Velho, 15 jan. 1996.

SÃO PAULO. Lei no 3.201, de 23 de dezembro de 1981. Dispõe sobre a parcela, pertencente aos municípios, do produto da arrecadação do Imposto de Circulação de Mercadorias. Diário Oficial do Estado de São Paulo, São Paulo, 23 dez. 1981.

SÃO PAULO. Lei no 8.510, de 29 de dezembro de 1993. Altera a Lei no 3.201, de 23 de dezembro de 1981, que dispõe sobre a parcela, pertencente aos municípios, do produto da arrecadação do Imposto sobre Operações Relativas à Circulação de Mercadorias e sobre Prestações de Serviços de Transporte Interestadual e Intermunicipal e de Comunicação - ICMS. Diário Oficial do Estado de São Paulo, São Paulo, 29 dez. 1993.

SEIFFERT, Mari Elizabete B. Gestão ambiental: instrumentos, esferas de ação e educação ambiental. São Paulo: Atlas, 2010.

SILVA JÚNIOR, Luiz Honorato da; SOBRAL, Eryka Fernanda. O ICMS socioambiental de Pernambuco: uma avaliação dos componentes socioeconômicos da política a partir do processo de Markov. Planejamento e Políticas Públicas, Fortaleza, n. 42, p. 189-217, jan./jun. 2014.

SILVA JÚNIOR, Luiz Honorato da et al. Avaliação dos impactos do ICMS Socioambiental na Criação de Unidades de Conservação e Unidades de Tratamento de Resíduos Sólidos em Pernambuco: uma análise a partir do método de diferenças-em-diferenças. Revista Econômica do Nordeste, Fortaleza, v. 44, n. 2, p. 559-574, abr./jun. 2013.

SILVA JÚNIOR, Luiz Honorato da et al. ICMS Socioambiental: uma avaliação da política no estado de Pernambuco. Revista Desenbahia, Salvador, v. 7, n. 13, p. 7-32, set. 2010. 
TOCANTINS. Lei no 1.323 , de 4 de abril de 2002. Dispõe sobre os índices que compõem o cálculo da parcela do produto da arrecadação do ICMS pertencente aos Municípios e adota outras providências. Diário Oficial do Estado do Tocantins, 4 abr. 2002.

TUPIASSU, Lise V. da C. Tributação ambiental: a utilização de instrumentos econômicos e fiscais na implementação do direito ao meio ambiente saudável. Rio de Janeiro: Renovar, 2006.

VIEIRA, Paulo Afonso E. Comunicação sobre a reforma tributária e unificação do IPI e ICMS, segundo os estados-membros da federação. Sequência, Florianópolis, v. 16, n. 31, p. 72-80, 1995.

Alexandrina Sobreira de Moura é doutora em ciências jurídicas, professora da Universidade Federal de Pernambuco (UFPE) e pesquisadora da Fundação Joaquim Nabuco (FJN). E-mail: alexandrina.sobreira@ gmail.com. 
